\title{
Effects of Bait Type and Conspecific Attraction in Diamondback Terrapin (Malaclemys terrapin) Bycatch
}

\author{
Aren J. Carpenter ${ }^{1 *}$, Meagan A. Thomas ${ }^{1}$, and Kristen K. Cecala ${ }^{2}$
}

Diamondback terrapins (Malaclemys terrapin) occur in coastal habitats along the Atlantic and Gulf coasts of the United States and have experienced range-wide population declines due to habitat loss and entrapment in commercial and recreational crab pots. While physical barriers have been proposed such as bycatch reduction devices, their effectiveness is skewed towards the largest individuals. Diamondback terrapins are attracted to the same bait used to lure crabs, thus causing them to become entrapped. An ex-situ experiment observing terrapin entry behavior to crab pots was performed. Twelve locally caught Diamondback terrapins were exposed to both consumable and conspecific - members of the same species - bait in a commercial crab pot. Interactions between terrapins and the crab pot were recorded, noting entries and escapes, investigations and social behavior such as trailing behavior (one individual following another into the pot) and investigation of conspecifics. Consumable baits had the greatest effect on terrapin entrapment relative to conspecifics or non-baited crab pots. Both entry and escape rates increased throughout the experiment, representing possible evidence of learned behavior. Expanded research on the relative attractiveness of baits should be conducted to determine if baits are available that minimize the attractiveness of crab pots to terrapins. This study demonstrates the potential of conscious bait choices and learned behavior as unexplored avenues for Diamondback terrapin conservation. The research should spur investigation into bait choices in conservation efforts for other at-risk bycatch species and provide rationale for investigating less conventional methods of conservation.

\section{INTRODUCTION}

Malaclemys terrapin (Diamondback terrapin; hereafter referred to as terrapins) are a uniquely estuarine turtle on the Atlantic and Gulf coasts of the United States threatened by activities associated with coastal development, such as commercial and recreational crabbing, habitat loss, and vehicle mortality (Ernst and Lovich, 2009). Diamondback terrapins are an important component in estuarine food webs because of their contribution to biomass production and partial maintenance of marsh grass populations through consumption of

Address correspondance to:

'Department of Biology, Davidson College, Davidson, NC 28035, USA

${ }^{2}$ Department of Biology, University of the South, Sewanee, TN 37383, USA

*arcarpenter18@alumni.davidson.edu

doi:10.22186/jyi.38.1.1-7

Acceptance date: June 2019

Publication date: January 2020 grazing periwinkle snails (Silliman and Bertness, 2002). The current range-wide declines in terrapin populations could contribute to collapses in coastal salt marsh ecosystems through the loss of biodiversity and marsh stability (Gibbons et al., 2001; Dorcas et al., 2007; CITES, 2013; IUCN, 2019).

Bycatch and subsequent drowning in both commercial and recreational crab pots appears to be a major factor in population decline (Bishop, 1983; Roosenburg et al., 1997; Wood, 1997; Roosenburg and Green, 2000; Tucker et al., 2001; Grosse et al., 2009; 2011; Rook et al., 2010; Bury, 2011; Hart and Crowder, 2011; Harden and Williard, 2012). Due to pronounced sexual dimorphism which results in significantly larger females, the mortality rates of males and juveniles in pots are high, creating biased populations of older female terrapins (Lovich and Gibbons, 1990; Dorcas et al., 2007). Terrapin population stability is highly dependent on the survival of breeding adults and juvenile recruitment, or entry into the breeding population. Therefore, mortality resulting from crab pots can devastate populations by altering age and sex ratios (Dorcas et al., 2007; Grosse et al., 2009; Crawford et al., 2014a). Reduced recruitment of males and young females into the breeding population will likely have detrimental effects on the stability of Diamondback terrapin populations, as has been documented in closely-related species (Congdon et al., 1993; Heppell, 1998; Gibbons et al., 2001; Dorcas et al., 2007; Crawford et al., 2014b). 
Bycatch reduction devices (BRDs) are rectangular openings that can be installed on to crab pot entrances to physically block terrapin entry due to the size of their carapace. These devices are more effective with increasing carapace size; therefore male and juvenile Diamondback terrapins are more at risk of capture than females (Roosenburg and Green, 2000; Wolak et al., 2010; Grosse et al., 2011; Hart and Crowder, 2011; McKee et al., 2016). Several characteristics of BRD usage have been researched, primarily, size and orientation. Previous studies found that smaller, vertically oriented BRDs are more effective in excluding terrapins (Wood, 1997; Roosenburg and Green, 2000; Butler and Heinrich, 2007; Dorcas et al., 2007; McKee et al., 2016). Despite BRDs appearing to have negligible effects on the number and size of crabs caught per pot, commercial and recreational crabbers have raised concerns over the possible negative effects that BRDs could have on Callinectes sapidus (Blue Crab) capture rates (Wood, 1997; Roosenburg and Green, 2000; Butler and Heinrich, 2007; Rook et al., 2010; Hart and Crowder, 2011). Crabbers located within the range of Diamondback terrapins remain skeptical towards the use of BRDs for fear of reducing the profitability of the fishery.

Therefore, other methods for minimizing terrapin entry and subsequent mortality in crab pots are vital to reducing long-term Diamondback terrapin population decline. For example, McKee et al. (2016) noted that different bait type influenced crab pot attractiveness, evidenced by recorded Diamondback terrapin entry rates. Bait type is an important and under-studied aspect of terrapin entrapment and presents a possible avenue for combating terrapin entrapment. Although commercial and recreational crabbers use a variety of bait types, standardization may be possible if one bait type proves less attractive to terrapins while maintaining crab catch rates. Spatial and temporal restrictions on crab trapping seasons, including distance-to-shore minimum distances and time of year, have also been recommended in conjunction with BRDs (Hart and Crowder, 2011).

Two factors hypothesized to contribute to terrapin entry were examined: consumable baits (chicken, fish, and shrimp) and conspecifics (members of the same species), as Diamondback terrapins are a social species (Seigel, 1980). Based on previous research, it was hypothesized that fish would be the most attractive bait type to terrapins (McKee et al., 2016). Researchers have noted abandoned crab pots that have increased numbers of individuals within a single pot, which suggests that social behavior resulting from the presence of conspecifics may increase Diamondback terrapin capture rates (Grosse et al., 2009). This hypothesis was tested by recording the effects of sex and abundance of conspecifics in crab pot attractiveness through Diamondback terrapin investigation and entry rates. It was additionally hypothesized that the presence of mature females would attract males. Total entries per individual and the proportion of investigations that yielded an entry were expected to vary by attractiveness of the bait. An under-studied aspect of Diamondback terrapin bycatch is the bait that inadvertently attracts terrapins to crab pots. As such, this represents a novel, effective approach for the conservation of Diamondback terrapins and other bycatch species.

\section{MATERIALS AND METHODS}

Twelve male Diamondback terrapins (mean plastron length [ventral shell] $=104 \mathrm{~mm}$, range $=94-111 \mathrm{~mm}$ ) were collected from the tidal creeks surrounding Kiawah Island, South Carolina, U.S.A. in May 2016 and released at their capture location in July 2016 . Seining was carried out by walking a $9 \mathrm{~m}$ net the length of a tidal creek. Morphological measurements of Diamondback terrapin individuals were taken in accordance with procedures outlined by Dorcas et al. (2007). The terrapins were transported in individual containers of water taken from their capture location to the South Carolina Aquarium, South Carolina, U.S.A. where they were housed for the duration of the study. Specimens were fed every two to three days with a variety of local fish sourced by the South Carolina Aquarium. For easy video identification, each terrapin individual was temporarily marked with a unique identification letter with an oil-based paint pen.

Terrapins were housed and tested in a circular, 1000 gal brackish water experimental tank (2.75 m diameter and $1 \mathrm{~m}$ deep) at the South Carolina Aquarium. Each trial involved all twelve male terrapins to ensure that trials were completed at naturally observed densities at Kiawah Island (10 - 15 individuals per group as noted by McKee et al., 2016). Trials were conducted twice per week so that the test population had at least 48 hours between trials and terrapins fasted for 48 hours before each trial. A commercial box crab pot $(60 \mathrm{~cm} \times 60 \mathrm{~cm} \times 45 \mathrm{~cm})$ was modified by extending a chimney above the water level to allow terrapins to breathe if they became entrapped. This allowed the trial to be continuous as no terrapins had to be removed due to a risk of drowning. The trial period began once the pot had been lowered into the tank or when conspecific bait was placed into the trap as bait. The trails lasted three hours. The crab pot openings were unaltered and were large enough to allow both entry and exit of all terrapins used in this study. Trials were recorded with a GoPro Hero 4 (GoPro, San Mateo, CA) camera mounted $10 \mathrm{~cm}$ above the chimney. The population of 12 terrapins was evaluated once for each of the nine bait types (control [no bait], chicken, shrimp, fish [freshwater, family Osmeridae], one female terrapin, two female terrapins, one male terrapin, two male terrapins, and one male terrapin with one female terrapin) with the order of trials randomly chosen and a control trial carried out at both the beginning and end of the study period (approximately two months) to quantify learned behavior. 

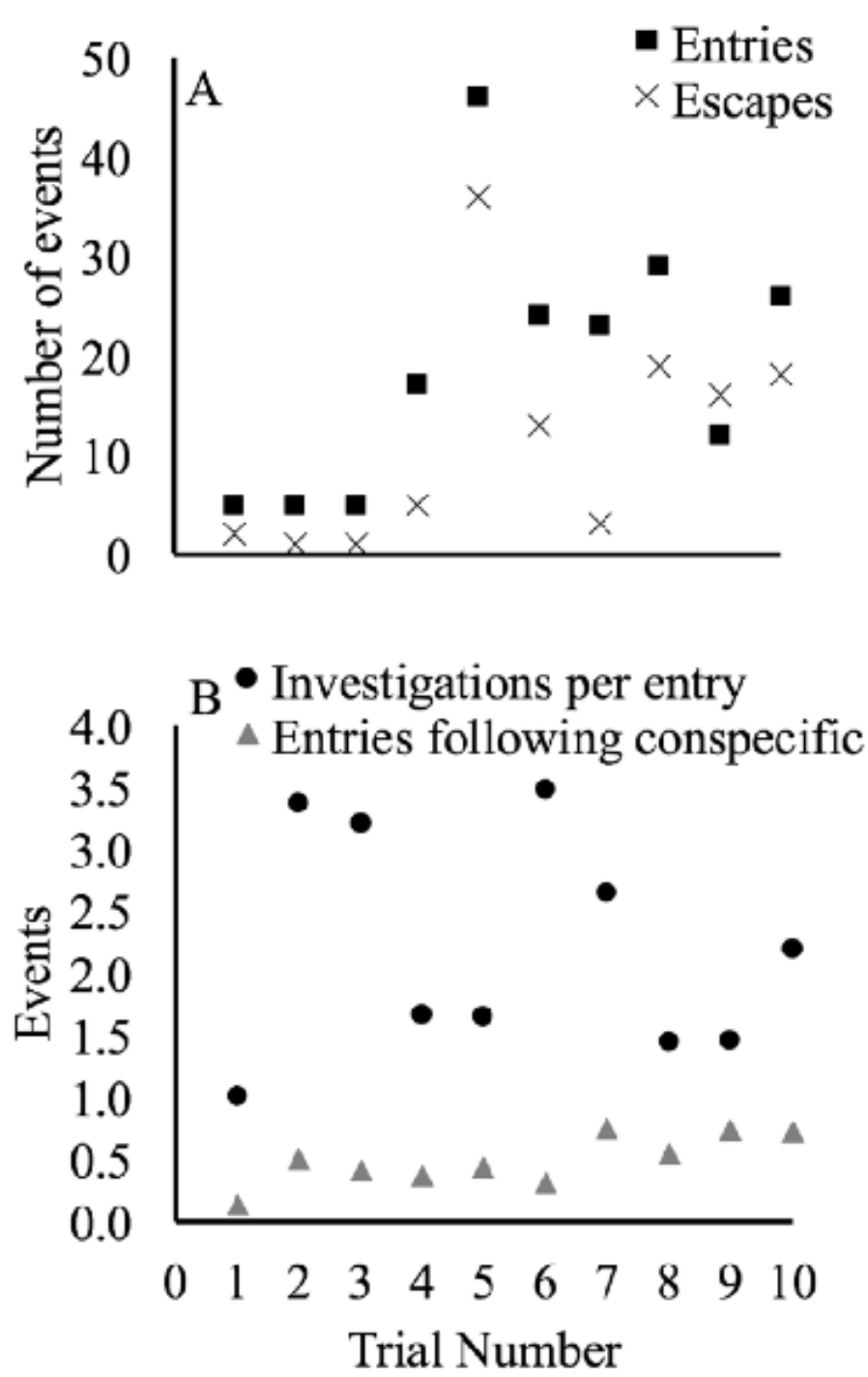

Figure 1. Terrapin entries and escapes $(A)$ increased with time (and trial number as a proxy measure of time) whereas investigations per entry and entries following a conspecific (B) did not. Linear trend lines are presented in (A) with the solid line indicating entries and dotted line indicating escapes. Trial number indicates the order of the treatments which were as follows: (1) control, (2) two female conspecifics, (3) one male conspecific, (4) fish bait, (5) chicken bait, (6) one female conspecific, (7) two male conspecifics, (8) shrimp bait, (9) one male and one female conspecific, and (10) control.

The trial order was as follows: control, two conspecific females, one conspecific male, fish, chicken, one conspecific female, two conspecific males, shrimp, one conspecific male and female, and control, for a total of ten trials. Diamondback terrapins used as conspecific bait were owned by the South Carolina Aquarium and had no known previous interactions with the wild caught individuals. Conspecific male Diamondback terrapins were never observed to escape from the crab pot even though their size allowed it, and conspecific females were too large to fit back into the lower portion of the pot. No specific precautions were, or had to be, taken to limit escapes by the conspecific bait. The responses of terrapins to different bait types was documented by observing total entries and the proportion of investigations (individuals were observed to investigate the entrances to the pot and attempting contact with captured individuals) resulting in entries to the crab pot. Observational information of terrapin behavior in and around crab pots was recorded. These measures were timed between beginning of trial and entry, total entries per individual, number of investigations, proportion of investigations resulting in an entry, trailing behavior (terrapins that entered within 60 seconds of another individual), and number of escapes per individual. All research described here was approved and permitted by the South Carolina Department of Natural Resources (\#SCI17-026) and the Davidson College Animal Care and Use Committee (\#6-16-02).

\section{Data Analysis}

Replicated controls (one trial at the beginning and end of the trial period) with no bait tested whether terrapins exhibited learned behavior over the course of our two-month study. All analyses were performed in R (R Core Team 2013). Before performing any analyses, Pearson's correlations were evaluated between trial number and our response variables. If we identified significant correlations $(\alpha<0.05)$, the residuals of that relationship were evaluated to correct for behavior that changed through time. Linear mixed models were initially used to fit data evaluating treatment effects using individual terrapin identification numbers as a random effect (package Ime4). Random effects and normality of these linear mixed models was evaluated and if normality was violated, the residuals were observed and a generalized mixed model was performed assuming a negative binomial error structure (package MASS). If random effects had distributions that overlapped with zero, the random effect was removed from the model structure. Analyses of deviance were performed to assess significance of bait type on our dependent variables (see procedure below). For linear mixed models, this was accomplished with Satterwaite's approximation of F-ratios. For negative binomial models, a chi-square of the residual deviance was used.

A two-step analysis was performed because of low power associated with limited sample sizes $(n=12)$. To reduce the number of pairwise comparisons, the overall class of bait (e.g. control, consumables, conspecifics) was tested to determine whether it significantly influenced the total number of entries or the proportion of entries per investigation. Pairwise Tukey post-hoc comparisons were then performed to determine which treatments differed from the others (package multcomp). Differences within these nested categories of bait type were evaluated. However, the low power of these intraclass comparisons should classify these results 

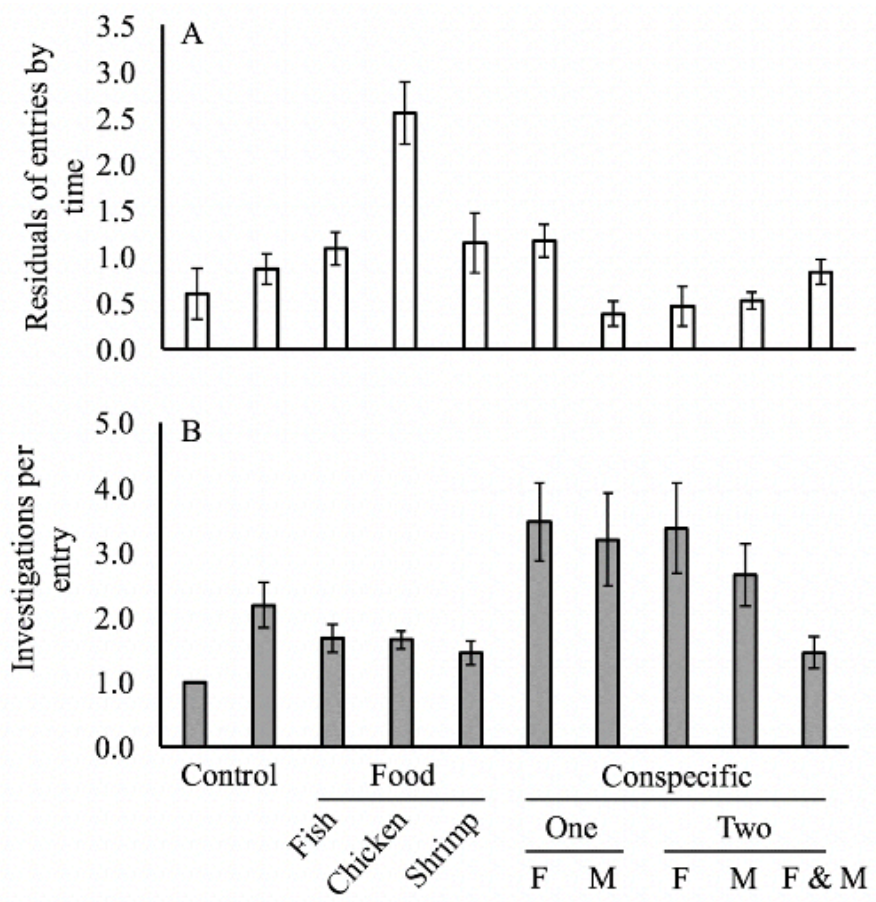

Figure 2. Treatment affected residuals of the relationship between time and terrapin entry into crab pots (A) and the number of investigations per entry (B). Residuals are presented in (A) because they were correlated with trial number, or time. For conspecific treatments, numbers represent the number of individuals placed into the traps and "F" or "M" represent the sex of these individuals. Error bars represent one standard error.

as preliminary rather than conclusive. Bonferroni corrections were also made to minimize Type 1 error, or the probability of finding a significant result where one does not exist.

\section{RESULTS}

Trial numbers $(n=10)$, as a proxy measure of time (ten trials conducted over two months), were significantly affected by entries per individual $\left(R^{2}=0.14, P<0.001\right)$, as well as escapes per individual $\left(R^{2}=0.12, P<0.001\right.$; Fig. $\left.1 \mathrm{~A}\right)$, but not by the proportion of investigations that resulted in an entry $\left(R^{2}=0.008, P=0.41\right)$ or the proportion of entries following another terrapin entry $\left(R^{2}=0.02, P=0.31\right.$; Fig. 1B). Terrapins entered the crab pot 2.15 times more on average (mean) in each successive trial, and escape rates increased by 1.88 times on average in each successive trial. Therefore, the residuals of the relationship between individual entries and time were used as the response variable for further analysis. Terrapin size was uncorrelated with entry or escape $\left(F_{1,10}=\right.$ $0.053, P=0.822 ; F_{1,10}=0.033, P=0.0860$ ).

Initially, a linear mixed model was used to assess the effect of treatment class (for example control, food bait, conspecifics) on individual entries using terrapin identification number as a random effect. A Shapiro Wilk's test was significant $(w=0.88, P<0.001)$ indicating non-normality of
Table 1. Pairwise comparisons (with Bonferroni corrections) between treatment types, food items, and characteristics of the conspecific treatments including number of terrapins and their sex. The estimate and standard error (SE) are provided for each pairwise comparison along with the test statistic $(z)$ and $p$-value. Significance following Bonferroni corrections were evaluated at $\alpha<0.05$.

\begin{tabular}{|c|c|c|c|c|}
\hline & Estimate & SE & $z$ & $p$ \\
\hline \multicolumn{5}{|l|}{ Entries } \\
\hline Control - Food & -0.78 & 0.27 & -1.89 & 0.011 \\
\hline Control - Terrapin & -0.08 & 0.29 & -0.28 & 0.968 \\
\hline Food - Terrapin & -0.86 & 0.20 & -4.24 & $<0.001$ \\
\hline \multicolumn{5}{|l|}{ Food Type } \\
\hline Fish - Chicken & -0.85 & 0.33 & -2.57 & 0.048 \\
\hline Fish - Shrimp & 0.05 & 0.39 & 0.14 & 0.999 \\
\hline Shrimp - Chicken & -0.80 & 0.32 & -2.47 & 0.063 \\
\hline \multicolumn{5}{|l|}{ Conspecifics } \\
\hline Number & -0.93 & 0.38 & -2.47 & 0.014 \\
\hline$M-F$ & -2.39 & 0.85 & -2.82 & 0.011 \\
\hline M - Mixed & 2.98 & 1.02 & 2.92 & 0.009 \\
\hline F - Mixed & 0.59 & 0.48 & 1.23 & 0.412 \\
\hline \multicolumn{5}{|c|}{ Investigations per entry } \\
\hline Control - Food & 0.17 & 0.23 & 0.72 & 0.750 \\
\hline Control - Terrapin & 0.36 & 0.21 & 1.70 & 0.200 \\
\hline Food - Terrapin & 0.52 & 0.16 & 3.23 & 0.003 \\
\hline \multicolumn{5}{|l|}{ Food Type } \\
\hline Fish - Chicken & 0.01 & 0.32 & 0.03 & 0.999 \\
\hline Fish - Shrimp & -0.14 & 0.34 & -0.43 & 0.972 \\
\hline Shrimp - Chicken & -0.14 & 0.33 & -0.41 & 0.975 \\
\hline \multicolumn{5}{|l|}{ Conspecifics } \\
\hline Number & -0.93 & 0.38 & -2.47 & 0.014 \\
\hline$M-F$ & -2.39 & 0.85 & -2.82 & 0.012 \\
\hline M - Mixed & 2.98 & 1.02 & 2.92 & 0.008 \\
\hline F - Mixed & 0.59 & 0.48 & 1.23 & 0.412 \\
\hline
\end{tabular}

the residuals, and a negative binomial error structure was implemented. Variance associated with terrapin number was negligible (variance $<0.0001 \pm<0.00001$ ). Treatment class significantly affected individual entry rates (deviance $=19.7$, $P<0.001$; Fig. 2A), and residuals of this model were evenly balanced around zero. As a class, consumable bait resulted in significantly higher entries than those of control or conspecific bait types (Table 1; Fig. 2A). Chicken resulted in 1.6 to 2.6 times more entries than shrimp or fish with similar numbers of entries. Neither conspecific sex nor number had a significant effect on terrapin entry rates (Sex: deviance $=3.09, P=0.21$; Number: deviance $=1.52, P=0.22$; Fig. $2 A)$. Overall, terrapin entry rates were highest in response to chicken bait and lowest in response to conspecifics.

In evaluating the proportion of investigations that yield- 
ed an entry, a linear mixed model revealed that terrapin identity had little effect on the model (variance $<0.0001 \pm$ $<0.00001)$ and the residuals of the relationship were nonnormal ( $w=0.86, P<0.001)$. Therefore, a negative binomial error structure was used. The proportion of investigations that resulted in an entry to the crab pot was significantly affected by treatment class (control, consumable, conspecific; deviance $=11.40, P=0.003$; Fig. 2B). Post hoc analyses revealed that the difference driving this result was between consumable bait and conspecifics (Table 1). No differences among consumable baits were identified by pairwise evaluation of food types. Within the conspecific treatments, the number of individuals was not influenced by the response variable (deviance $=0.22, P=0.64$ ), but mixed sex resulted in significantly fewer entries per investigations (deviance $=$ 10.9, $P=0.004$; Fig. 2B).

Terrapins were observed investigating the trap where entrapped terrapins were located rather than the actual entrances. More time was spent by individuals investigating pots with entrapped conspecifics than bait or control trials, but entry rates for this subset were the lowest (Fig. 2). Conspecific bait had the highest level of investigations but the lowest level of entries. In some cases, this number was lower than that of the control trials. Within the conspecific subset, a single female as bait had the highest level of entry.

\section{DISCUSSION}

Diamondback terrapin bycatch in commercial and recreational crab pots is a contributing factor in regional population declines, and the baits used to attract crabs represent possible approaches for reducing terrapin bycatch. It was hypothesized that fish would be the most attractive bait to terrapins and that the presence of conspecifics in a pot would increase bycatch. Diamondback terrapin entrapment events increased in frequency over the duration of the study period (Fig. 1A), suggesting that repeated exposure to the crab pots increased an individual's likelihood of entering a pot. Learned entry behavior resulting from positive pot interactions, such as consuming bait, may have increased entry rates over time. Evidence for this mechanism was present in the second control trial, the last trial conducted temporally, in which no bait was present, but terrapins entered the trap at a similar frequency to the previous four trials which used bait. This phenomenon was also qualitatively observed in McKee et al. (2016). While no studies have quantitatively examined behavioral plasticity in terrapin interactions with crab pots, previous research has identified plasticity as a driving force in promoting phenotypic changes in amphibian and reptile behavior, including other turtle species, in response to changing environments (Borenstein et al., 2008; Urban et al., 2013). Increased escape rates over the study period may be evidence that repeated experience with crab pots without mortality could lead to learned escape behav- iors that could reduce mortality. At least in shallow waters, the use of chimneys associated with crab pots is supported by these results because chimneys provide opportunities for the terrapins to access air while learning to escape. However, this presents a challenge in situ for conservation efforts, as physically modifying crab pots would be difficult and expensive.

Conspecific social interactions were observed in previous terrapin studies (Grosse et al., 2009; McKee et al., 2016). While entries classified as trailing behavior did not significantly increase over time, there was a slight positive trend, suggesting that it may be a factor in increased entries over time, but not the main factor (Fig. 1B). An interesting component of social behavior observed in this study relates to interactions between entrapped and free terrapins. While comparisons among conspecific attraction are preliminary, conspecific identity may play a supplementary role to bait type in determining the attractiveness of a crab pot. Female conspecifics had the highest level of entry, suggesting that sexual attraction could be a factor in male terrapin investigations as social interactions have been observed in mating rituals (Seigel, 1980). Further investigation into the role of female and mixed sex conspecific bait is warranted due to the role that social interactions play in Diamondback terrapin behavior. However, due to current declines of terrapins, researchers must carefully design studies to limit the effects of removing mature females from a population. The ability of Diamondback terrapins to learn over time through interactions with crab pots and conspecifics impacted the ability to draw reliable inferences, and future studies should address this.

Terrapin entry and investigation of crab pots was impacted by consumable and conspecific bait types. Fish and shrimp had similar levels of investigations and entries, but chicken had the highest number of terrapin entries, in contrast to previous research suggesting that fish was the most attractive bait for Diamondback terrapins (Fig. 2A and 2B; McKee et al., 2016). Fish was also identified as the most attractive bait for commercial Blue Crab trapping; therefore, it may represent the best option for decreasing Diamondback terrapin attraction to crab pots while not decreasing crab attraction (McKee et al., 2016). Indeed, many previous studies on BRD efficacy have used fish as bait because it is commonly used by commercial crabbers, but many species of fish, smelt, mackerel, menhaden, herring, among others, are used which may complicate conservation efforts (Roosenburg et al., 1997; Anderson and McDonald, 2008; Morris et al., 2011; McKee et al., 2016). In general, fish bait is less expensive than chicken. Additionally, menhaden is one of the most common species used in commercial crabbing, though recreational crabbers appear to use baits that are readily available, including fish, chicken, and clams (Anderson, 2014). Most crabbers purchase their bait from local 
wharfs or vendors, where market values regularly fluctuate, making quantifying average bait prices difficult. Further studies are needed to determine Diamondback terrapin attraction to these common crab bait species to determine if a bait is available that is unattractive to terrapins, but attractive to crabs. These results can then inform conservation efforts to decrease Diamondback terrapin decline in populations affected by crab pot bycatch.

Numerous studies have identified entrapment as a threat to terrapin populations. The use of devices to physically block entry, mainly BRDs, has presented promising conservation avenues for larger individuals in a terrapin population (Roosenburg and Green, 2000; Butler and Heinrich, 2007; Rook et al., 2010; Bury, 2011; Hart and Crowder, 2011; McKee et al., 2016). A combination of conservation measures remains the most likely to be successful option for terrapin management, but one controllable and overlooked factor is bait type. Previous research identified spatial and temporal restrictions on crab trapping seasons, including distanceto-shore minimum distances and time of year restrictions, paired with BRDs and fish or shrimp bait to be a possible conservation option for limiting entrapment of Diamondback Terrapins (Hart and Crowder, 2011). It is in the best interest of both commercial and recreational crabbing communities to support these conservation efforts as research by Morris and colleagues (2011) demonstrated that the presence of live terrapins decreases the number of Blue Crabs captured. Additional studies should expand on this work to explore the mechanisms of terrapin entrapment (that is, what attracts terrapins to crab pots and what variables affect entrapment) to better understand the nuanced effect that bait type may have on entrapment. Furthermore, factors that encourage escape by terrapins should also receive additional attention to prevent mortality associated with terrapin bycatch. This research presents a synergistic approach to terrapin conservation and will provide useful results for terrapins and crabbers alike. It serves as a model system for limiting bycatch in any fishing industry through small, individual-based changes that can affect the larger industry.

\section{ACKNOWLEDGMENTS}

We thank Cris Hagen and the Davidson College Herpetology Laboratory for assistance in terrapin capture and release as well as South Carolina Aquarium and Kelly Thorvalson for housing and feeding the terrapins and for use of a crab pot. Funding was provided by a Jolley Foundation grant. Research was conducted under a SCDNR Scientific Terrapin Collection Permit and complied with Davidson College Animal Care and Use Committee guidelines. We thank Shannon Pittman for her comments on this manuscript.

\section{REFERENCES}

Anderson, J. D. and McDonald, D. L. (2008). Notes on food attraction and the demographics of Blue Crab (Callinectes sapidus) trapping in Tres
Palacios Bay, Texas. Texas Journal of Science, 60, 271-280.

Anderson, A. N. (2014). Development of an alternative bait for the Louisiana commercial blue crab (Callinectes sapidus) fishery. LSU Master's Theses, 3460, 1-68.

Bishop, J. M. (1983). Incidental capture of Diamondback Terrapin by crab pots. Estuaries, 6, 426-430, available: www.doi.org/10.2307/1351402.

Borenstein, E., Feldman, M. W., Aoki, K. (2008). Evolution of learning in fluctuating environments: When selection favors both social and exploratory individual learning. Evolution, 62, 586-602, available: www. doi.org/10.1111/j.1558-5646.2007.00313.x.

Butler, J. A. and Heinrich, G. L. (2007). The effectiveness of bycatch reduction devices on crab pots at reducing capture and mortality of Diamondback Terrapins (Malaclemys terrapin) in Florida. Estuaries and Coasts, 30, 179-185, available: www.doi.org/10.1007/bf02782978.

Bury, R. B. (2011). Modifications of traps to reduce bycatch of freshwater turtles. The Journal of Wildlife Management, 75, 3-5, available: www. doi.org/10.1002/jwmg.31.

Congdon, J. D., Dunham, A. E., Van Loben Sels, R. C. (1993). Delayed sexual maturity and demographics of Blanding's turtles (Emydoidea blandingii): Implications for conservation and management of longlived organisms. Conservation Biology, 7, 826-833, available: www. doi.org/10.1046/j.1523-1739.1993.740826.x.

Crawford, B. A., Maerz, J. C., Nibbelink, N. P., Norton, T. M., Buhlmann, K. A. (2014a). Estimating the consequences of multiple threats and management strategies for semi-aquatic turtles. Journal of Applied Ecology, 51, 359-366, available: www.doi.org/10.1111/1365-2664.12194.

Crawford, B. A., Maerz, J. C., Nibbelink, N. P., Norton, T. M., Buhlmann, K. A., Albeke, S. E. (2014b). Hot spots and hot moments of Diamondback Terrapin road-crossing activity. Journal of Applied Ecology, 51, 367-375, available: www.doi.org/10.1111/1365-2664.12195.

Dorcas, M. E., Willson, J. D., Gibbons, J. W. (2007). Crab trapping causes population decline and demographic changes in Diamondback Terrapins over two decades. Biological Conservation, 137, 334-340, available: www.doi.org/10.1016/j.biocon.2007.02.014.

Ernst, C. H. and Lovich, J. E. (2009). Turtles of the United States and Canada. Baltimore, Maryland: The Johns Hopkins University Press.

Gibbons, J. W., Lovich, J. E., Tucker, A. D., FitzSimmons, N. N., Greene, J. L. (2001). Demographic and ecological factors affecting conservation and management of the Diamondback Terrapin (Malaclemys terrapin) in South Carolina. Chelonian Conservation and Biology, 4, 66-74.

Grosse, A. M., Maerz, J. C., Hepinstall-Cymerman, J., Dorcas, M. E. (2011). Effects of roads and crabbing pressures on Diamondback Terrapin populations in coastal Georgia. The Journal of Wildlife Management, 75, 762-770, available: www.doi.org/10.1002/jwmg.104.

Grosse, A. M., Van Dijk, J. D., Holcomb, K. L., Maerz, J. C. (2009). Diamondback Terrapin mortality in crab pots in a Georgia tidal marsh. Chelonian Conservation and Biology, 8, 98-100, available: www.doi. org/10.2744/ccb-0729.1.

Harden, L. A. and Williard, A. S. (2012). Using spatial and behavioral data to evaluate the seasonal bycatch risk of Diamondback Terrapins Malaclemys terrapin in crab pots. Marine Ecology Progress Series, 467, 207-217, available: www.doi.org/10.3354/meps09958.

Hart, K. M. and Crowder, L. B. (2011). Mitigating by-catch of Diamondback Terrapins in crab pots. The Journal of Wildlife Management, 75, 264272, available: www.doi.org/10.1002/jwmg.49.

Heppell, S. S. (1998). Application of life-history theory and population model analysis to turtle conservation. Copeia, 1998, 367-375, available: www.doi.org/10.2307/1447430.

Iverson, J. B. (1982). Biomass in turtle populations: A neglected subject. Oecologia, 55, 69-76, available: www.doi.org/10.1007/bf00386720.

McKee, R. K., Cecala, K. K., Dorcas, M. E. (2016). Behavioral interactions of Diamondback Terrapins with crab pots demonstrate that bycatch reduction devices reduce entrapment. Aquatic Conservation: Marine and Freshwater Ecosystems, 26, 1081-1089, available: www.doi. org/10.1002/aqc. 2587.

Morris, A. S., Wilson, S. M., Dever, E. F., Chambers, R. M. (2011). A test of bycatch reduction devices on commercial crab pots in a tidal marsh 


\section{$\stackrel{\bullet \bullet \circ}{\vdots . J Y I}$ Journal of Young Investigators}

creek in Virginia. Estuaries and Coasts, 34, 386-390, available: www. doi.org/10.1007/s12237-010-9330-1.

Rook, M. A., Lipcius, R. N., Bronner, B. M., Chambers, R. M. (2010). Bycatch reduction device conserves Diamondback Terrapin without affecting catch of Blue Crab. Marine Ecology Progress Series, 409, 171-179, available: www.doi.org/10.3354/meps08489.

Roosenburg, W. M., Cresko, W., Modesitte, M., Robbins, M. B. (1997). Diamondback Terrapin (Malaclemys terrapin) mortality in crab pots. Conservation Biology, 11, 1166-1172, available: www.doi.org/10.1046/ j.1523-1739.1997.95443.x.

Roosenburg, W. M. and Green, J. P. (2000). Impact of a bycatch reduction device on Diamondback Terrapin and Blue Crab capture in crab pots. Ecological Applications, 10, 882-889, available: www.doi. org/10.1890/1051-0761(2000)010[0882:ioabrd]2.0.co;2.

Siegel, R. A. (1980). Courtship and mating behavior of the Diamondback Terrapin Malaclemys terrapin tequesta. Journal of Herpetology, 14, 420-421, available: www.doi.org/10.2307/1563703.

Silliman, B. R. and Bertness, M. D. (2002). A trophic cascade regulates salt marsh primary production. Proceedings of the National Academy of Sciences of the United States of America, 99, 10500-10505, available: www.doi.org/10.1073/pnas.162366599.

Tucker, A. D., Gibbons, J. W., Greene, J. L. (2001). Estimates of adult survival and migration for Diamondback Terrapins: conservation insight from local extirpation within a metapopulation. Canadian Journal of Zoology, 79, 2199-2209, available: www.doi.org/10.1139/z01-185.

Urban, M. C., Richardson, J. L., Freidenfelds, N. A. (2013). Plasticity and genetic adaptation mediate amphibian and reptile responses to climate change. Evolutionary Applications, 7, 88-103, available: www. doi.org/10.1111/eva.12114.

Wolak, M. E., Gilchrist, G. W., Ruzicka, V. A., Nally, D. M., Chambers, R. M. (2010). A contemporary, sex-limited change in body size of an estuarine turtle in response to commercial fishing. Conservation Biology, 24, 1268-1277, available: www.doi.org/10.1111/j.15231739.2010.01469.x.

Wood, R. C. (1997). The impact of commercial crab traps on northern Diamondback Terrapins, Malaclemys terrapin terrapin. Proceedings: Conservation, Restoration, and Management of Tortoises and Turtles - An International Conference, 21-27. 